\title{
Aplicação foliar de prolina no crescimento e fisiologia do milho verde cultivado em solo salinizado
}

Francisco de Assis da Silva ${ }^{1}$, Francisco Hevilásio Freire Pereira ${ }^{2}$, José Eustáquio Campos Júnior ${ }^{3}$, Jackson Silva Nobrega ${ }^{4}$, Mirandy dos Santos Dias ${ }^{1}$

${ }^{1}$ Universidade Federal de Campina Grande - UFCG, Centro de Tecnologia e Recursos Naturais - CTRN, PB. ${ }^{2}$ Universidade Federal de Campina Grande - UFCG, Centro de Ciências e Tecnologia Agroalimentar - CCTA, PB. ${ }^{3}$ Escola Superior de Agricultura "Luiz de Queiroz" - ESALQ, SP. ${ }^{4}$ Universidade Federal da Paraíba - UFPB, Centro de Ciências Agrárias - CCA, PB.

\section{Resumo}

O milho (Zea mays L.) é uma das culturas mais cultivadas no mundo. No Brasil, este cereal tem ampla diversidade de uso. A maioria das áreas onde há produção de milho, utiliza-se a irrigação, entretanto, quando realizada de forma inadequada, torna-se preponderante para a salinização dos solos. Assim, objetivou-se avaliar o efeito da aplicação foliar de prolina no crescimento e fisiologia da cultura do milho cultivado em solo salinizado. $O$ experimento foi conduzido no Centro de Ciência e Tecnologia Agroalimentar (CCTA), pertencente à Universidade Federal de Campina Grande (UFCG), Pombal, PB, no período de março a abril de 2015, utilizando-se a variedade de milho AG 1051. Os tratamentos foram constituídos por dois níveis de salinidade do solo, $(3,26$ e $0,86 \mathrm{dS} / \mathrm{m})$ e cinco concentrações de prolina $(0 ; 2,5 ; 5,0 ; 7,5$ e $10 \mathrm{mmol}$ $\left.\mathrm{L}^{-}{ }^{1}\right)$ aplicada via foliar nas plantas de milho. $O$ delineamento experimental foi inteiramente casualizado, no esquema fatorial $2 \times 5$, com quatro repetições. Foi observado um maior crescimento e acúmulo de massa quando as plantas foram conduzidas em solo de menor salinidade ( $C E=0,86 \mathrm{dS} / \mathrm{m}$ ). A transpiração foi influenciada pela salinidade e pela concentração de prolina. A maior taxa de concentração intercelular de $\mathrm{CO}_{2}(\mathrm{Ci})$ foi obtida na concentração de $7,5 \mathrm{mmol} \mathrm{L}^{-}{ }^{1}$ prolina. As concentrações de prolina não influenciaram nos aspectos de crescimento e acúmulo de massa do milho.

Palavras-chave: aminoácido; trocas gasosas; Zea mays L.

\section{Proline of leaf application on growth and physiology of green corn on soil salinity different levels}

\begin{abstract}
Corn (Zea mays L.) is one of the most cultivated crops in the world. In Brazil, this cereal has a wide diversity of use. Most of the areas where maize production is used is irrigation, however, when performed inadequately it becomes preponderant for salinization of soils. The effect of proline foliar application on the growth and physiology of the green maize cultivated in salinized soil was evaluated. The experiment was conducted at the Center for Agro-Food Science and Technology (CCTA), belonging to the Federal University of Campina Grande (UFCG), Pombal, PB, from March to April 2015, using maize variety AG 1051. The treatments consisted of two levels of soil salinity $(3.26$ and $0.86 \mathrm{dS} / \mathrm{m})$ and five concentrations of proline $\left(0,2.5,5.0,7.5\right.$ and $\left.10 \mathrm{mmol} \mathrm{L}^{-1}\right)$ applied by leaf on corn plants. The experimental design was completely randomized, in the $2 \times 5$ factorial scheme, with four replications. A higher growth and mass accumulation was observed when the plants were conducted in soil of lower salinity (CE $=0.86 \mathrm{dS} / \mathrm{m}$ ). Transpiration was influenced by salinity and proline concentration. The highest rate of intercellular $\mathrm{CO} 2$ concentration $(\mathrm{Ci})$ was obtained at the concentration of $7.5 \mathrm{mmol} \mathrm{L}^{-1}$ proline. Proline concentrations did not influence the growth and mass accumulation aspects of maize.
\end{abstract}

Keywords: amino acid; gas exchange; Zea mays L. 


\section{Introdução}

O milho é uma das culturas mais cultivadas no mundo, ocupando uma posição de destaque entre os cereais. No Brasil, $15 \%$ da produção de milho é utilizada para o consumo humano. A produtividade de milho na safra de 2016/2017 foi de aproximadamente $5.562 \mathrm{~kg} \mathrm{ha}^{-1}$ resultando em uma produção de $97.842,8 \mathrm{mil}$ toneladas de grãos (CONAB, 2018). No Brasil apesar de se ter uma expansão de apenas 3,86 de área cultivada, nas últimas décadas a produção brasileira de milho vem aumentando em torno de 4,61 vezes. Em face do aumento da população mundial, a previsão é que a produção desse cereal continue crescendo cada vez mais (GALVÃO et al., 2014; GERLAND et al., 2014).

$A$ área de cultivo do milho, em sua maior parte, é realizada por irrigação que por sua vez se não for efetuada de forma correta torna-se um ato preponderante para salinização dos solos. As plantas estão constantemente expostas a estresses abióticos e, dentre eles, o estresse salino é um dos que mais comprometem o crescimento e a produtividade das culturas em todo o mundo (ISLÃ; ARAGUÉS, 2010). Em âmbito mundial, estima-se que 831 milhões de hectares sejam afetados por sais. Nas regiões áridas e semiáridas os solos são afetados pela salinidade em face da baixa precipitação pluviométrica bem como pelas altas temperaturas locais (D'ODORICO et al., 2013; ABDELGAWAD et al., 2016). No Brasil, ainda não foram realizados estudos detalhados quanto ao mapeamento e a identificação de áreas salinizadas, porém estimase que cerca de 20 a $25 \%$ das áreas irrigadas apresentem problemas com salinidade do solo, sendo a região Nordeste a mais afetada (FAO, 2005). Os estados de Pernambuco, Ceará e Paraíba de 25 a $40 \%$ das áreas irrigadas são afetadas por altas concentrações de sais ou sódio nos solos (TAVARES FILHO et al., 2012).

A cultura do milho é considerada moderadamente sensível a salinidade, apesentando uma salinidade limiar da água de $1,1 \mathrm{dS} \mathrm{m}^{-1}$ e do solo de $1,7 \mathrm{dS} \mathrm{m}^{-1}$ (AYERS; WESTCOT, 1999). Dentre os processos fisiológicos afetados pela salinidade destaca-se a fotossíntese, que pode ser inibida pelo acúmulo de íons $\mathrm{Na}^{+}$e/ou $\mathrm{Cl}^{-}$nos cloroplastos, os quais afetam os processos bioquímicos e fotoquímicos envolvidos na fotossíntese (TAIZ et al., 2017). Como resposta ao estresse salino, como também a outros tipos de estresse abióticos, as plantas por sua vez, tem a capacidade de desenvolver mecanismos de defesa capazes de combatê-los e desta forma minimizar os efeitos deletérios causados pelos excessos de sais tanto do solo como da água de irrigação. $\mathrm{O}$ acúmulo de solutos orgânicos ou osmólitos no vacúolo das plantas é um exemplo eficaz de resposta ao estresse salino. Dentre as respostas metabólicas envolvidas no processo de aclimatização do estresse, o estudo da prolina vem sendo bastante documentado (MANE et al., 2011).

Para a absorção de água, as plantas precisam manter o potencial hídrico interno abaixo daquele verificado no solo. Para isso, requer uma diminuição no potencial osmóticohídrico através da absorção de íons do solo ou até mesmo pela síntese e acúmulo de solutos orgânicos compatíveis, assim mantendo o tugor e o crescimento (TAIZ et al., 2017). Os carboidratos solúveis, aminoácidos, glicina-betaina e prolina são alguns dos solutos orgânicos comumente encontrados nas plantas sob condições salinas, atuando no processo de ajuste osmótico em muitas culturas (ASHRAF et al., 2011).

Sendo assim, ao invés da utilização do melhoramento genético para promover o aumento da produtividade da cultura sob estresse salino, tem-se sugerido como alternativa a aplicação destes compostos de forma exógena na planta, alavancando a produtividade (ASHRAF; FOOLAD, 2007;). Desta forma, a aplicação foliar de prolina em uma cultura que seja sensível ou moderamente sensível a salinidade poderá aumentar os nutrientes na folha e consequentemente atenuar os efeitos deletérios do estresse salino. Diante do exposto, objetivouse, avaliar o efeito da aplicação foliar de prolina no crescimento e fisiologia da cultura do milho cultivado em solo salinizado.

\section{Material e Métodos}

O experimento foi conduzido no Centro de Ciências e Tecnologia Agroalimentar (CCTA) pertencente a Universidade Federal de Campina Grande (UFCG) Pombal-PB, no período de março a abril de 2015, onde, utilizou-se o hibrido de milho verde 'AG 1051', próprio para a produção de milho verde e produção de grãos.

O cultivo foi realizado em vasos com capacidade de $8 \mathrm{dm}^{3}$, preenchidos com solo classificado como vertissolo, textura argilosa, cujo resultado da análise de fertilidade do solo realizado previamente antes da instalação do experimento foram: $\mathrm{pH}=7,52 ; \mathrm{P}=149,1 ; \mathrm{K}^{2+}=$ 319,$2 ; \mathrm{Na}^{2+}=284,1 \mathrm{mg} \mathrm{dm}{ }^{-3} ; \mathrm{Ca}^{2+}=39,9 \mathrm{mg} \mathrm{dm}^{-3}$; 
$\mathrm{Mg}^{2+}=8,9 ; \mathrm{Al}^{3+}=0,00 ; \mathrm{SB}=50,85 ; \mathrm{CTC}=50,85 ; \mathrm{V}$ $=100 \mathrm{Cmol} \mathrm{dm}^{-3}$; PST $=2,0$ e M.O $=8,23 \mathrm{gkg}^{-1}$. Análise de sólidos solúveis: Solo 1: $\mathrm{SO}_{4}{ }^{2-}=0,02$ $\mathrm{mmol}_{\mathrm{c}} \mathrm{dm}^{-3} ; \mathrm{CO}_{3}{ }^{2-}=0,00 \mathrm{mmol}_{\mathrm{c}} \mathrm{dm}^{-3} ; \mathrm{Cl}^{-}=40,00$ $\mathrm{mmol}_{\mathrm{c}} \mathrm{dm}^{-3} ; \mathrm{HCO}_{3}^{-}=3,13 \mathrm{mmol}_{\mathrm{c}} \mathrm{dm}^{-3} ; \mathrm{RAS}=$ 15,38; SATURAÇÃO (\%) $=92,0$; C.E (extrato) $=$ $3,26 \mathrm{dS} / \mathrm{m} ; \mathrm{pH}$ (extrato) $=6,99 ; \mathrm{Ca}^{+2}=7,50 \mathrm{mmol}_{\mathrm{c}}$ $\mathrm{dm}^{-3} ; \mathrm{Mg}^{+2}=1,88 \mathrm{mmol}_{\mathrm{c}} \mathrm{dm}^{-3} ; \mathrm{Na}^{+}=33,29 \mathrm{mmol}_{\mathrm{c}}$ $\mathrm{dm}^{-3} ; \mathrm{K}^{+}=0,94 \mathrm{mmol}_{\mathrm{c}} \mathrm{dm}^{-3} ;$ salinidade $=$ muito alta; classificação $=\mathrm{C}_{4}$.

Solo 2: $\mathrm{SO}_{4}{ }^{2-}=0,06 \mathrm{mmol}_{\mathrm{c}} \mathrm{dm}^{-3} ; \mathrm{CO}_{3}{ }^{2-}=$ $0,00 \mathrm{mmol}_{\mathrm{c}} \mathrm{dm}^{-3} ; \mathrm{Cl}^{-}=10,00 \mathrm{mmol}_{\mathrm{c}} \mathrm{dm}^{-3} ; \mathrm{HCO}_{3}^{-}=$ $3,13 \mathrm{mmol}_{\mathrm{c}} \mathrm{dm}^{-3} ;$ RAS $=5,23$; SATURAÇÃO $(\%)=$ 84,0; C.E (extrato) $=0,86 \mathrm{dS} / \mathrm{m} ; \mathrm{pH}$ (extrato) $=$ 7,75; $\mathrm{Ca}^{+2}=2,50 \mathrm{mmol}_{\mathrm{c}} \mathrm{dm}^{-3} ; \mathrm{Mg}^{+2}=1,88 \mathrm{mmol}_{\mathrm{c}}$ $\mathrm{dm}^{-3} ; \mathrm{Na}^{+}=7,74 \mathrm{mmol}_{\mathrm{c}} \mathrm{dm}^{-3} ; \mathrm{K}^{+}=0,44 \mathrm{mmol}_{\mathrm{c}} \mathrm{dm}^{-}$ ; ; salinidade $=$ alta; classificação $=$ C3.

$O$ incremento na salinidade do solo 1 foi obtido irrigando-se com água salina de condutividade elétrica de $2,0 \mathrm{dS} \mathrm{m}^{-1}$ durante 30 dias antes do plantio do milho. Para a salinização da água de irrigação foi utilizado cloreto de sódio $(\mathrm{NaCl})$. Durante a realização do experimento foram registradas temperaturas entre $31,3{ }^{\circ} \mathrm{C}$ a $32,8^{\circ} \mathrm{C}$, umidade relativa de 42,1 a $49,9 \%$.

Os tratamentos foram constituídos por dois níveis de salinidade do solo, ( $C E=3,26$ e 0,86 $\mathrm{dS} / \mathrm{m})$ e cinco concentrações de prolina $(0 ; 2,5$; 5,$0 ; 7,5$ e $10 \mathrm{mmol} \mathrm{L}^{-1}$ ) aplicada via foliar nas plantas de milho. $O$ delineamento experimental foi inteiramente casualizado, no esquema fatorial $2 \times 5$, com quatro repetições, totalizando 40 unidades experimentais.

A prolina foi aplicada a cada 7 dias na superfície da folha a partir do décimo dia após a semeadura (DAS), em volume que variou de 50 a $100 \mathrm{ml}$ por planta de acordo com o crescimento da planta, sendo realizada 3 aplicações no decorrer do experimento (aos 10, 17 e 25 dias).

A semeadura foi realizada diretamente no vaso a uma profundidade de $2,0 \mathrm{~cm}$, colocando-se vinte e cinco sementes por vaso com intuito de se avaliar inicialmente o efeito da salinidade sobre percentagem de emergência das sementes de milho. Os vasos foram dispostos no espaçamento de $0,5 \times 0,5 \mathrm{~m}$. A emergência, acima de $50 \%$ das plantas foi observada 4 DAS. 0 desbaste foi realizado no sétimo dia após a semeadura (DAS) deixando duas plantas por vaso. Os macros e micronutrientes foram aplicados juntamente com a água de irrigação, os valores totais foram: $307,0 \mathrm{~g}$ de $\mathrm{KH}_{2} \mathrm{PO}_{4}, 399,0 \mathrm{~g}$ de $\mathrm{CH}_{4}$ $\mathrm{N}_{2} \mathrm{O}, 223 \mathrm{~g}$ de $\mathrm{KCl}, 286,0 \mathrm{~g}$ de $\left(\mathrm{NH}_{4}\right)_{6} \mathrm{M}_{07} \mathrm{O}_{24} 4 \mathrm{H}_{2} \mathrm{O}$, $9,5 \mathrm{~g}$ de $\mathrm{ZNSO}_{4} 7 \mathrm{H}_{2} \mathrm{O}$ e $13,0 \mathrm{~g}$ de $\mathrm{H}_{3} \mathrm{BO}_{3}$.
A irrigação foi realizada de acordo com a necessidade da cultura, utilizando-se o método da lisimetria, sendo realizadas duas aplicações diárias ( 8 h 00 e 17 h 00). A quantidade de água aplicada por vaso variou no transcorrer do experimento de 0,5 a 2,0 L por dia totalizando uma quantidade de 50 litros de água por vaso durante os 30 dias.

As avaliações foram realizadas aos 30 DAS, em uma planta por vaso, coletada cortandoas rente ao solo. Nessas plantas foram avaliadas: Altura de planta (AP) medida rente a solo até o ápice da folha principal, diâmetro de caule (DC) mensurado através de um paquímetro digital, número de folhas por planta (NF) contabilizando apenas as folhas boas e desprezando as folhas secas, massa seca de folha (MSF), massa seca do caule (MSC), massa seca total (MST) e área foliar $(\mathrm{AF})$.

A área foliar foi obtida relacionando-se a massa seca de 8 discos foliares de área conhecida $\left(1,41 \mathrm{~cm}^{2}\right)$ com a massa seca total das folhas por planta de acordo com a equação 1.

AFP $=(M S F \times$ AFD $) / M S D$

Onde: $A F P=$ Área foliar $\left(\mathrm{cm}^{2}\right.$ por planta), MSF = Massa seca das folhas (g), AFD = Área foliar dos $\operatorname{discos}\left(\mathrm{cm}^{2}\right)$, MSD = Massa seca dos discos (g).

O número de folhas foi obtido por contagem, considerando o tamanho mínimo da folha formada. O diâmetro do caule foi medido com paquímetro digital no colo da planta. A massa seca total foi determinada pela soma da massa seca das folhas e do caule, obtidas após secagem em estufa, com circulação de ar a $70^{\circ} \mathrm{C}$, por 72 horas. Os valores foram expressos em $g$ por planta.

As avaliações fisiológicas foram realizadas aos 30 (DAS). Nesta ocasião foram medidas as variáveis de trocas gasosas a exemplo da fotossíntese (A), a condutância estomática (gs), a transpiração (E) e a concentração intercelular de $\mathrm{CO}_{2}(\mathrm{Ci})$, com analisador de gás no infravermelho (IRGA) LCpro ${ }^{+}$(Analytical Development, Kings Lynn, UK) com fonte de luz constante de 2.000 $\mu \mathrm{mol}$ de fótons $\mathrm{m}^{-2} \mathrm{~s}^{-1}$ e concentração de $\mathrm{CO}_{2}$ ambiente. Para realização das leituras, foram utilizadas as folhas intermediárias, entre a quarta e sexta folha contada do ápice para a base do colmo, em uma planta por vaso.

Os dados foram submetidos a análise de variância pelo teste $f$. Em seguida aplicado teste Tukey a $5 \%$ de probabilidade, utilizando programa estatístico SISVAR, (FERREIRA, 2011). 


\section{Resultados e Discussão}

Crescimento e acúmulo de massa.

Não houve interação significativa entre a salinidade do solo e as concentrações de prolina para nenhuma das características de crescimento e acúmulo de massa. No entanto, quando estudado os fatores isolados, foi observado diferença significativa para os níveis de salinidade para o diâmetro do colmo (DC), massa seca do colmo (MSC), massa seca da folha (MSF), massa seca total (MST) e área foliar (AF) (Tabela 1).

Tabela 1. Resumo da análise de variância para altura de planta (AP), diâmetro do colmo (DC), número de folhas (NF), massa seca de folhas (MSF), massa seca do colmo (MSC), massa seca total (MST) e área foliar (AF) aos 30 DAS.

\begin{tabular}{llccccccc}
\hline Fonte de & \multirow{2}{*}{ GL } & \multicolumn{7}{c}{ QM } \\
\cline { 3 - 8 } Variação & & AP & DC & NF & MSF & MSC & MST & AF \\
\hline S. solo (S) & 1 & $19,18^{\text {ns }}$ & $62,17^{* *}$ & $0,40^{\text {ns }}$ & $67,34^{* *}$ & $28,17^{* *}$ & $182,4^{* *}$ & $4231730,1^{* *}$ \\
Prolina (P) & 4 & $44,16^{\text {ns }}$ & $1,34^{\text {ns }}$ & $0,18^{\text {ns }}$ & $4,59^{\text {ns }}$ & $0,38^{\text {ns }}$ & $5,58^{\text {ns }}$ & $288898,4^{\text {ns }}$ \\
SXP & 4 & $49,15^{\text {ns }}$ & 2,83 ns & $0,46^{\text {ns }}$ & $4,16^{\text {ns }}$ & $0,98^{\text {ns }}$ & $6,96^{\text {ns }}$ & $261521,3^{\text {ns }}$ \\
Resíduo & 30 & 39,62 & 93,09 & 1,10 & 5,46 & 1,82 & 11,75 & 343301,9 \\
\hline CV\% & - & 11,27 & 6,93 & 9,53 & 20,12 & 23,03 & 19,61 & 20,13 \\
\hline
\end{tabular}

*, ${ }^{* *}$-significativos a 5 e $1 \%$ de probabilidade pelo teste $\mathrm{F}$.

Para o diâmetro do colmo, em plantas cultivada em solo de condutividade elétrica $(3,26$ $\mathrm{dS} / \mathrm{m}$ ) obtiveram uma média de $24,16 \mathrm{~mm}$ sendo menor quando comparado com o solo de menor condutividade elétrica $(0,86 \mathrm{dS} / \mathrm{m})$ que obteve uma média de 26,66 mm (Figura 1A). Este efeito está associado à toxidez promovida por íons, especialmente o $\mathrm{Na}+\mathrm{e}$ o $\mathrm{Cl}^{-}$, ocorrendo redução no crescimento da planta. A salinidade do solo tende a comprometer o crescimento vegetal, afetando o crescimento em altura e o diâmetro caulinar em função da agressividade do excesso de sais contidos no solo.

Para a massa seca do colmo (Figura 1B) foi observado o valor de $6,71 \mathrm{~g}$ para o solo de $(0,86 \mathrm{dS} / \mathrm{m})$ e $5,03 \mathrm{~g}$ para o solo de $(3,26 \mathrm{dS} / \mathrm{m})$. Já para massa seca da folha (Figura 1C) e massa seca total (Figura 1D), os maiores valores encontrados foram 12,91 e 19,62 g respectivamente para 0 solo de menor condutividade $(0,86 \mathrm{dS} / \mathrm{m})$. Assim foi observado que as plantas cultivadas no solo de menor condutividade obtiveram maiores médias. Redução geral no acúmulo de massa seca na planta tem sido verificado por diversos autores, a exemplo de Jiang et al. (2016) ao trabalhar com milho observou uma redução de $26 \%$ na massa seca da parte aérea, Pitan et al. (2013) observaram reduções de 27 e $15 \%$ variando de acordo com o genótipo, Lima et al. (2007) verificaram uma redução de $66,94 \%$ na biomassa seca da parte aérea do feijão vigna (cultivar quarentinha), quando o mesmo foi irrigado com água de condutividade elétrica de $5,0 \mathrm{dS} / \mathrm{m}$, em comparação a testemunha de $0,5 \mathrm{dS} / \mathrm{m}$. Bem como Bayuelo Jimenes et al. (2012). 
Figura 1. Diâmetro do colmo, massa seca do colmo, massa seca da folha, massa seca total e área foliar de milho em função da salinidade do solo aos 30 DAS

A

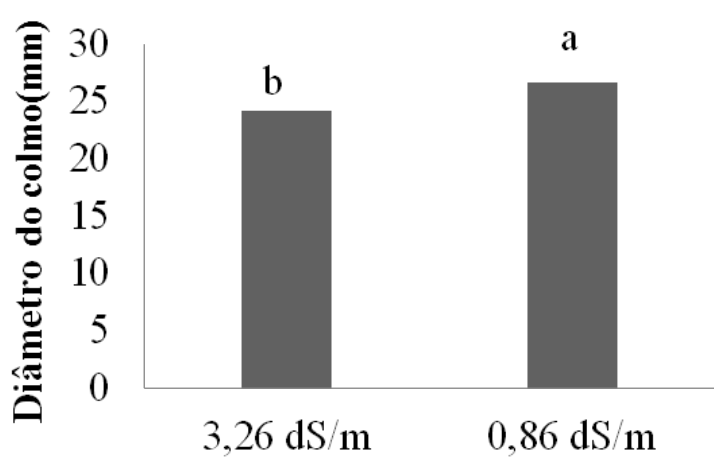

Salinidade do solo

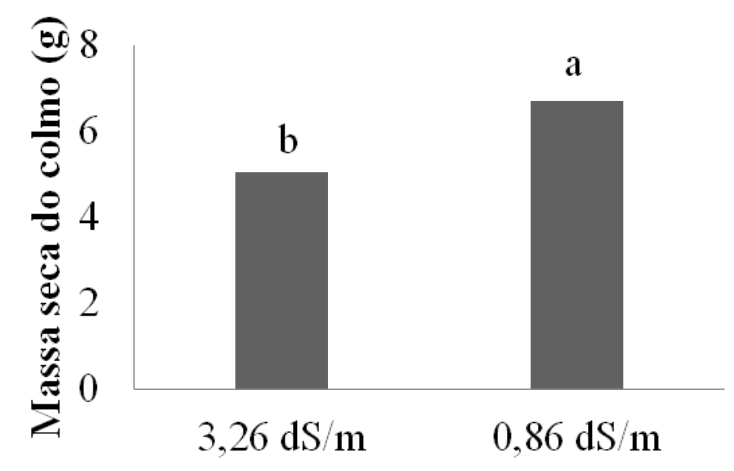

Salinidade do solo

$\mathrm{C}$
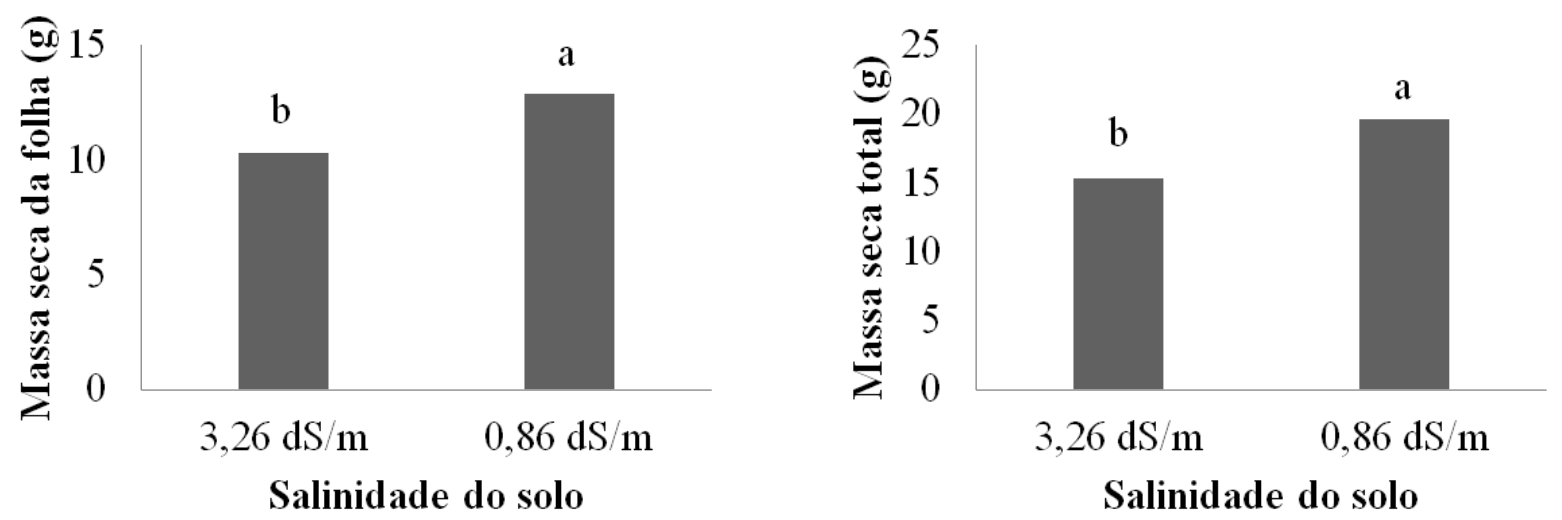

$\mathrm{E}$

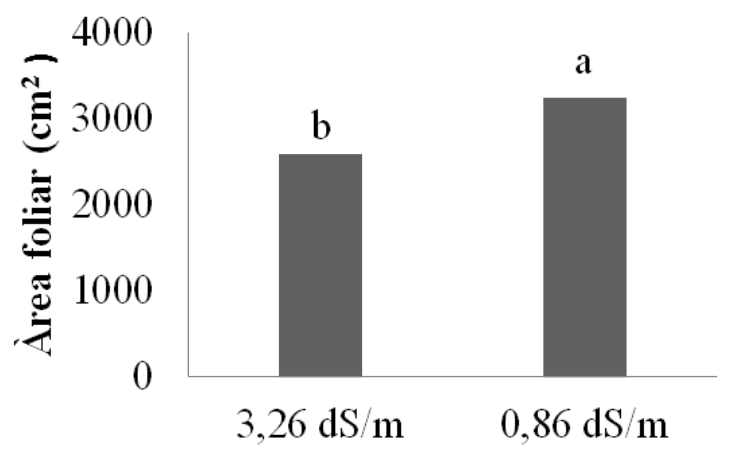

Salinidade do solo

A área foliar (Figura 1E) demonstrou uma sensibilidade ao fator salinidade, reduzindo consideravelmente com o aumento da condutividade elétrica. A redução foi de $20 \%$ quando comparado o cultivo em solo com $(3,26$ $\mathrm{dS} / \mathrm{m}$ ) em relação a condutividade de $0,86 \mathrm{dS} / \mathrm{m}$ (Figura 3E). A redução na área foliar é um sinal de efeitos do estresse salino, mesmo em genótipos tolerantes (MANE et al., 2011). É frequente encontrar reduções na área foliar em plantas de milhos sob estresse salino (GONDIM et al., 2013; SILVA et al., 2014), essa redução em plantas expostas a salinidade tem sido atribuída à diminuição na divisão celular e expansão da superfície da folha, que ocorre nas fases iniciais da exposição ao estresse salino bem como um mecanismo de defesa para reduzir as perdas de água por transpiração (TAIZ et al., 2017). 
A altura de planta não sofreu influência da salinidade do solo. Os valores médios de altura de planta cultivadas em solo com $(3,26 \mathrm{dS} / \mathrm{m})$ foram menores do que quando cultivadas em solo de $0,86 \mathrm{dS} / \mathrm{m}$ (Figura 2).

Figura 2. Número de folhas e altura de planta em função da salinidade do solo aos 30 DAS

A

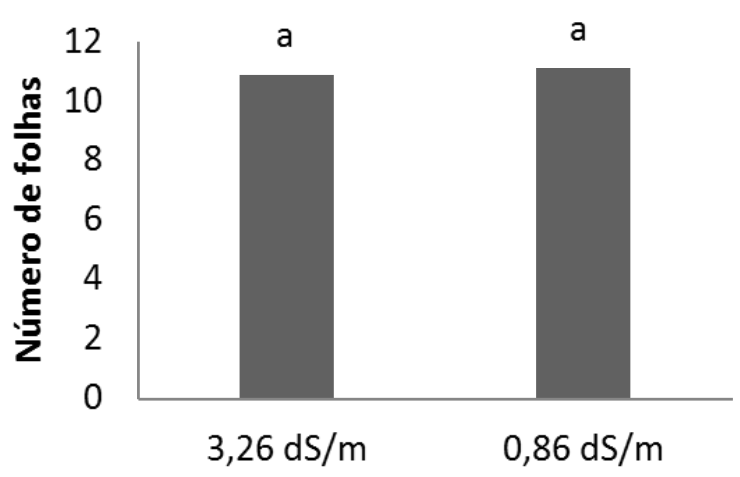

Salinidade do solo

Na Tabela 2, encontra-se as médias para as variáveis de crescimento que não apresentaram diferença significativa quando da aplicação das concentrações de prolina.

A altura média de planta foi de $58,97 \mathrm{~cm}$ na concentração de $7,5 \mathrm{mmol} \mathrm{L}^{-1}$, mesmo sem diferirem estatisticamente observou-se um aumento percentual de $7 \%$ quando comparado com a concentração de $0 \mathrm{mmol} \mathrm{L}^{-1}$. Uma outra característica observada é que ao aplicar a concentração de $10 \mathrm{mmol} \mathrm{L}^{-1}$ houve uma redução no crescimento do milho quando comparado com as demais concentrações estudadas. Isso incide dizer que concentrações elevadas de prolina podem diminuir o crescimento em altura da cultura do milho.

Para o diâmetro do colmo, seguiu a mesma tendência da variável altura de planta, obtendo

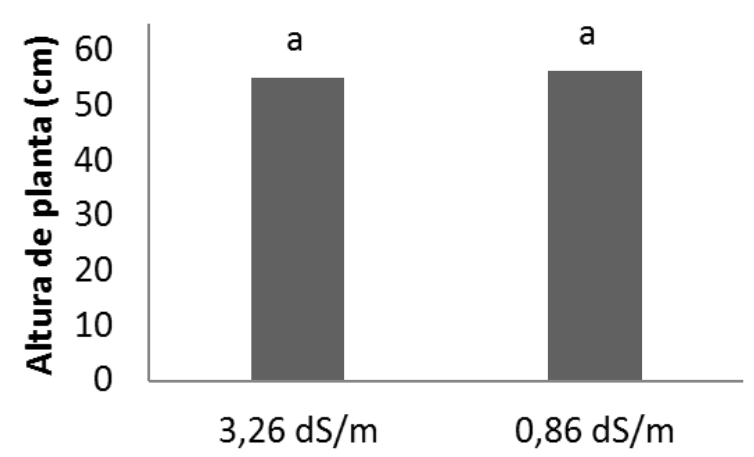

Salinidade do solo

valores de $26,04 \mathrm{~mm}$ (maior valor encontrado) na concentração de 7,5 $\mathrm{mmol} \mathrm{L}^{-1}$ a 25,18 mm (menor valor encontrado) nas plantas tratadas com a concentração $10,0 \mathrm{mmol}^{\mathrm{L}^{-1}}$. Em trabalho realizado por Lacerda (2013), ao trabalhar com aplicação exógena de prolina em plantas de melancieira sob aplicação de água salina $(4,0$ $\mathrm{dS} / \mathrm{m}$ ), foi observado um incremento de $22,6 \%$ na massa seca do caule quando comparada com a concentração de $0 \mathrm{mmol} \mathrm{L}^{-1}$. Já em melão amarelo, a aplicação da prolina na forma exógena foi eficiente em reduzir o efeito estressante causado pela salinidade da água de irrigação até a concentração de $12 \mathrm{mmol} \mathrm{L}^{-1}$ por planta, correspondendo a um aumento na produção de 2,5 t ha- ${ }^{1}$ (LACERDA et al., 2012).

Tabela 2. Médias não significativas para as variáveis altura de planta (AP), diâmetro de caule (DC), número de folhas (NF), massa seca de folha (MSF), massa seca de caule (MSC), matéria seca total (MST) e área foliar (AF) em plantas de milho submetido a diferentes concentrações de prolina. CCTA/UFCG, Pombal, 2015

\begin{tabular}{cccccccc}
\hline Prolina & AP & DC & NF & MSF & MSC & MST & AF \\
\hline 0 & $54,80 \mathrm{a}$ & $25,20 \mathrm{a}$ & $11,12 \mathrm{a}$ & $11,22 \mathrm{a}$ & $6,17 \mathrm{a}$ & $17,39 \mathrm{a}$ & $2814,04 \mathrm{a}$ \\
2,5 & $55,82 \mathrm{a}$ & $25,60 \mathrm{a}$ & $10,75 \mathrm{a}$ & $10,69 \mathrm{a}$ & $5,55 \mathrm{a}$ & $16,24 \mathrm{a}$ & $2680,56 \mathrm{a}$ \\
5,0 & $56,96 \mathrm{a}$ & $25,40 \mathrm{a}$ & $11,00 \mathrm{a}$ & $11,40 \mathrm{a}$ & $5,91 \mathrm{a}$ & $17,32 \mathrm{a}$ & $2859,16 \mathrm{a}$ \\
7,5 & $58,97 \mathrm{a}$ & $26,04 \mathrm{a}$ & $11,00 \mathrm{a}$ & $12,60 \mathrm{a}$ & $5,86 \mathrm{a}$ & $18,46 \mathrm{a}$ & $3159,34 \mathrm{a}$ \\
10,0 & $52,69 \mathrm{a}$ & $25,18 \mathrm{a}$ & $11,12 \mathrm{a}$ & $12,14 \mathrm{a}$ & $5,84 \mathrm{a}$ & $17,99 \mathrm{a}$ & $3043,62 \mathrm{a}$ \\
\hline Cv\% & 11,27 & 6,93 & 9,20 & 19,84 & 22,40 & 19,61 & 19,84 \\
Média & 55,85 & 25,41 & 11,00 & 11,61 & 5,87 & 17,48 & 2911,34 \\
\hline
\end{tabular}

Médias seguidas da mesma letra, minúscula na coluna, não diferem entre si, pelo teste de Tukey a $5 \%$ de probabilidade 
Alguns trabalhos demostram que o excesso de prolina em plantas pode causar efeito tóxico. Roy et al (1993) ao realizar trabalho com arroz (Oriza sativa), observaram que $30 \mathrm{mM}$ de prolina foi a concentração mais eficaz para melhorar a germinação e o crescimento das plantas sob estresse salino.

A prolina tem a propriedade de proporcionar ajustamento osmótico sem causar injúria aos tecidos em comparação ao efetuado por íons. Plantas de milho respondem à salinização pela manutenção de maiores concentrações de sacarose e prolina, visto que o nível de prolina aumenta com a salinização e com o tempo de exposição das plantas ao sal, sugerindo um papel protetor da prolina. O acúmulo de compostos orgânicos nitrogenados deve refletir num mecanismo protetor ao qual se inclui acúmulo de solutos compatíveis como a prolina e outros aminoácidos, refletindo como um mecanismo osmorregulatório (KUZNETSOV; SHEVYAKOVA, 1997).

\section{Trocas gasosas}

Verificou-se efeito individual para os fatores salinidade do solo e as diferentes concentrações de prolina para concentração intercelular de $\mathrm{CO}_{2}$ (Ci). Houve interação significativa entre a salinidade do solo e as concentrações de prolina apenas para transpiração (E). Para as demais variáveis estudadas não foi observado efeito significativo (Tabela 3).

Tabela 3. Resumo da análise de variância para fotossíntese (A), condutância estomática (gs), transpiração (E), e concentração interna de $\mathrm{CO}_{2}$ (Ci) aos 30 DAS.

\begin{tabular}{cccccc}
\hline Fonte de & \multirow{2}{*}{$\mathrm{GL}$} & \multicolumn{2}{c}{$\mathrm{QM}$} \\
\cline { 3 - 6 } Variação & & $\mathrm{A}$ & $\mathrm{gs}$ & $\mathrm{E}$ & $\mathrm{Ci}$ \\
\hline S. solo (S) & 1 & $58,51^{\text {ns }}$ & $0,54^{\text {ns }}$ & $11,83^{* *}$ & $649,8^{\text {ns }}$ \\
Prolina (P) & 4 & $34,68^{\text {ns }}$ & $0,65^{\text {ns }}$ & $0,56^{\text {ns }}$ & $1273,6^{* *}$ \\
S x P & 4 & $5,43^{\text {ns }}$ & $0,37^{\text {ns }}$ & $2,40^{* *}$ & $292,20^{\text {ns }}$ \\
Resíduo & 30 & 34,56 & $0,81^{\text {ns }}$ & 0,37 & $226,3^{\text {ns }}$ \\
\hline CV \% & - & 20,19 & 31.9 & 12,18 & 16,14 \\
\hline
\end{tabular}

*, **-significativos a 5 e $1 \%$ de probabilidade pelo teste $\mathrm{F}$

A maior taxa de concentração intercelular de $\mathrm{CO}_{2}\left(104,5 \mu \mathrm{mol} \mathrm{mol}^{-1}\right)$ foi obtida na concentração de $7,5 \mathrm{mmoL}^{-1}$ de prolina, ou seja, observa-se um comportamento crescente até a concentração de $7,5 \mathrm{mmoL}^{-1}$ em seguida apresentando um decréscimo na concentração de $10 \mathrm{mmoL}^{-1}$ (Figura 3). 0 incremento percentual proporcionado na taxa de $\mathrm{Ci}$ pela concentração de $7,5 \mathrm{mmoL}^{-1}$ em relação a concentração de $0 \mathrm{mmoL}^{-1}$ foi de $15 \%$. Com relação a salinidade do solo observou-se que não houve diferença significativa entre ambas obtendo médias de 96,05 e 90,35 $\mu \mathrm{mol} \mathrm{mol}^{-1}$ para o solo $1(3,26 \mathrm{dS} / \mathrm{m})$ e solo $2(0,86 \mathrm{dS} / \mathrm{m})$ respectivamente. 
Figura 3. Concentração intercelular de $\mathrm{CO}_{2}$ em função da aplicação de diferentes concentrações de prolina aos 30 DAS.

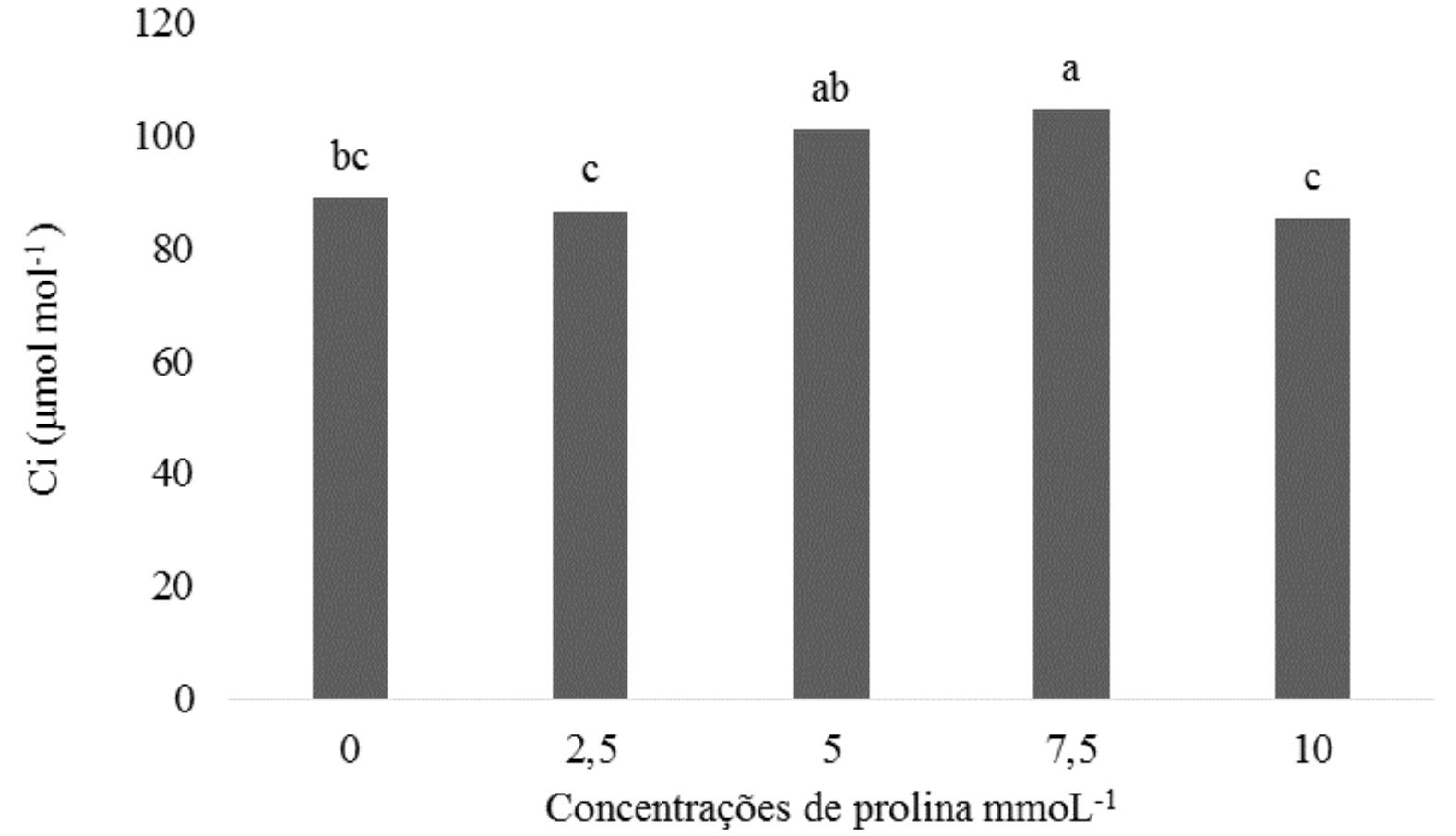

Para variável transpiração (E) foi observado interação significativa entre os dois fatores em estudos, onde o solo com menor condutividade $(0,86 \mathrm{dS} / \mathrm{m})$ quando em consonância com as concentrações de $0,2,5,5,0$ e $10 \mathrm{mmoL}^{-1}$ favoreceram as maiores taxas de transpirações nas plantas de milho. Embora as concentrações de prolina tenham sido estatisticamente semelhantes a concentração de $0 \mathrm{mmoL}^{-1}$ dentro do solo de menor condutividade elétrica $(0,86 \mathrm{dS} / \mathrm{m})$ foi a que proporcionou a maior taxa de transpiração $\left(5,77 \mathrm{mmol} \mathrm{m}^{-2} \mathrm{~s}^{-1}\right)$ e a concentração de $7,5 \mathrm{mmoL}^{-1}$ a menor $(5,02 \mathrm{mmol}$ $\left.\mathrm{m}^{-2} \mathrm{~s}^{-1}\right)$. Já para o solo de maior condutividade $(3,26 \mathrm{dS} / \mathrm{m})$ foi observado que a maior taxa de transpiração ocorreu na concentração de 7,5 $\mathrm{mmoL}^{-1}$ e a menor na concentração de $5,0 \mathrm{mmoL}^{-}$ 1 (Figura 3). 0 incremento percentual obtido através do solo de menor condutividade em relação ao de maior condutividade foi de $39,2,9$, 35 e $16 \%$ para as concentrações de 0, 2,5, 5,0 e $10 \mathrm{mmoL}^{-1}$ de propina respectivamente. Quando a planta é submetida a eventos de salinidade, seja do solo ou da água de irrigação, esta tende a reduzir o seu desempenho fisiológico, o que se torna natural devido ao estresse sofrido pela cultura. Sob condições salinas, os sais acumulados nas folhas podem afetar diversos processos fisiológicos das plantas de forma negativa, ao reduzir a fotossíntese, ou positiva, desde que não sejam atingidos níveis tóxicos, pela promoção do ajuste osmótico, que contribui para manutenção da turgescência e do crescimento (LACERDA et al., 2013). 
Figura 3. Transpiração em plantas de milho cultivadas em solo com diferentes níveis de salinidade e tratadas com diferentes concentrações de prolina. CCTA/UFCG, Pombal, 2015

$\square$ Solo $1:(3,26 \mathrm{dS} / \mathrm{m}) \quad \square$ Solo $2(0,86 \mathrm{dS} / \mathrm{m})$

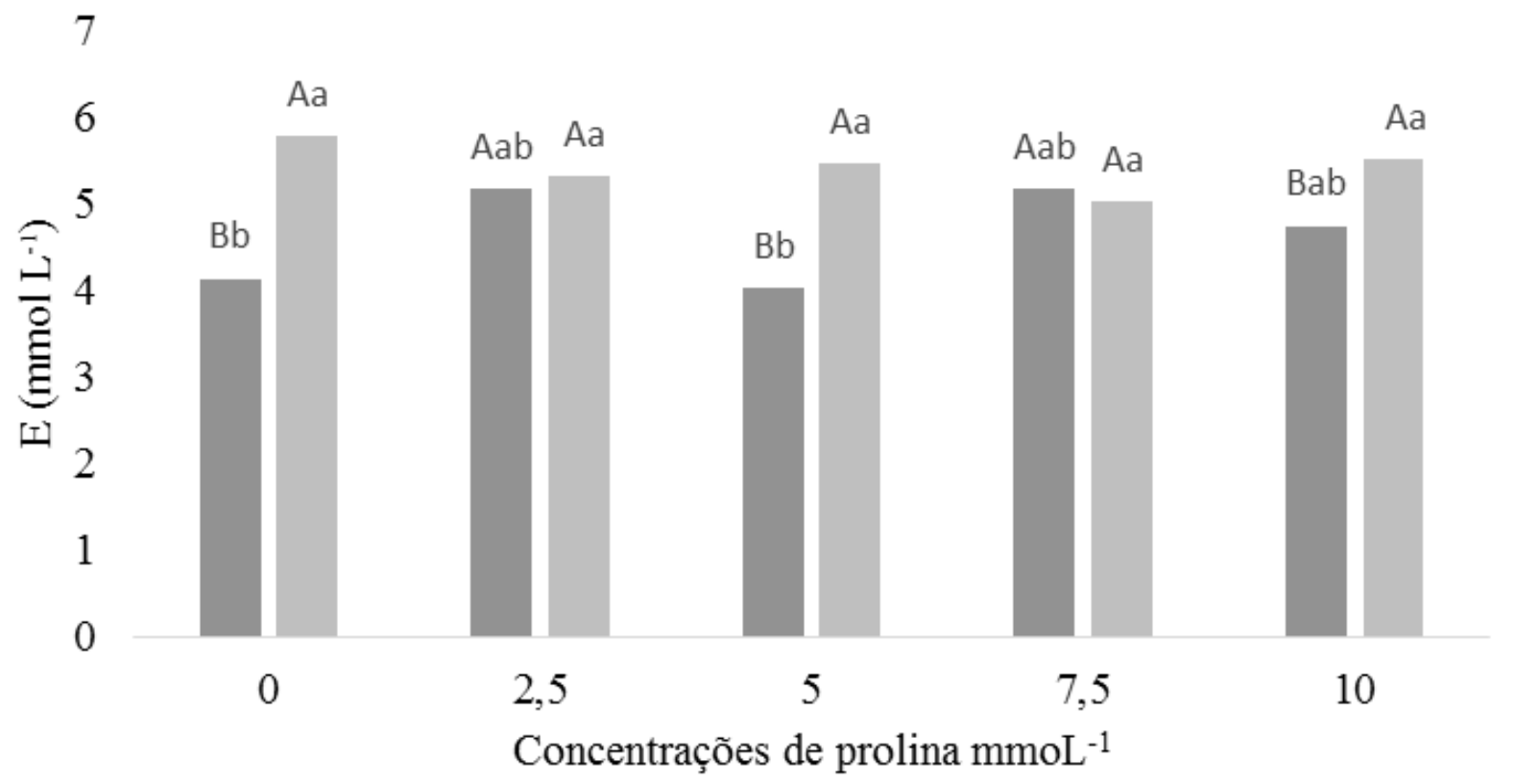

Médias seguidas da mesma letra, minúscula para concentrações de prolina e maiúscula entre solo, não diferem entre si, pelo teste de Tukey a $5 \%$ de probabilidade.

As variáveis fotossíntese (A) e condutância estomática (gs) não foram significativas para nenhum dos fatores em estudos, porém é importante observar que o solo de menor condutividade $(0,86 \mathrm{dS} / \mathrm{m})$ obteve médias superiores ao solo de maior condutividade. Os valores de fotossíntese foram de 28,25 e $29,96 \mu \mathrm{mol} \mathrm{m} \mathrm{s}^{-2}$ para o solo $1(3,26$ $\mathrm{dS} / \mathrm{m})$ e solo $2(0,86 \mathrm{dS} / \mathrm{m})$ respectivamente. Já para condutância estomática foi de 0,27 e 0,29 umol mol ${ }^{-1}$ para ambos os solos. Resultados semelhantes foram encontrados por Gomes et al. (2011) ao trabalharem com milho sob duas condutividades elétricas da água de irrigação $(0,8$ e 5,0 dS/m) observaram que não houve efeito da salinidade da água de irrigação para a fotossíntese liquida. Deste modo pode-se dizer que as plantas de milho tiveram uma boa tolerância aos níveis de sais na condição desse estudo. Deve-se salientar que a irrigação durante o experimento foi realizada com água de abastecimento local contendo aproximadamente $0,3 \mathrm{dS} / \mathrm{m}$.
Apesar de não apresentar efeito significativo a fotossíntese se comportou de forma semelhante para diferentes concentrações de prolina, porém, foi observada uma média de $30,29 \mu \mathrm{mol} \mathrm{m}^{-2} \mathrm{~s}^{-1}$ quando utilizada a concentração de $10 \mathrm{mmol} \mathrm{L}^{-1}$, apresentando um aumento percentual de $6,8 \%$ quando relacionada a concentração de $10 \mathrm{mmol} \mathrm{L}^{-1}$ e $0 \mathrm{mmol} \mathrm{L}^{-1}$ (Tabela 3). Lacerda (2013) trabalhando com melancia, observou que a aplicação exógena de prolina até a dose de $8,02 \mathrm{mmol} \mathrm{L}^{-1}$ foi eficiente em maximizar os processos fisiológicos da planta, reduzindo, assim, o efeito estressante causado pela salinidade da água de irrigação na melancieira. Acima de $8,02 \mathrm{mmol} \mathrm{L}^{-1}$ houve uma redução na fotossíntese, possivelmente, devido a redução do potencial osmótico-hídrico abaixo do tolerado pela cultura da melancieira provocado pelo aumento na concentração de prolina. 
Tabela 3. Fotossíntese liquida (A) e Condutância estomática (gs) em plantas de milho submetidos a diferentes concentrações de prolina. CCTA/UFCG, Pombal, 2015.

\begin{tabular}{ccc}
\hline Prolina $\left(\mathrm{mmol} \mathrm{L}^{-1}\right)$ & $\mathrm{A}$ & gs \\
\hline 0 & $28,26 \mathrm{a}$ & $0,2637 \mathrm{a}$ \\
2,5 & $30,58 \mathrm{a}$ & $0,2918 \mathrm{a}$ \\
5,0 & $27,03 \mathrm{a}$ & $0,2643 \mathrm{a}$ \\
7,5 & $29,36 \mathrm{a}$ & $0,3118 \mathrm{a}$ \\
10,0 & $30,29 \mathrm{a}$ & $0,2831 \mathrm{a}$ \\
\hline Cv\% & 19,73 & 31,07 \\
Média & 29,10 & 0,2830 \\
\hline
\end{tabular}

Médias seguidas da mesma letra, minúscula na coluna, não diferem entre si, pelo teste de Tukey a $5 \%$ de probabilidade.

O maior valor de condutância estomática foi de $0,3118 \mathrm{~mol} \mathrm{~m}^{-2} \mathrm{~s}^{-1}$ na concentração de 7,5 mmol $\mathrm{L}^{-1}$, mesmo não diferindo estatisticamente observa-se um incremento proporcionado pela concentração de $7,5 \mathrm{mmol} \mathrm{L}^{-1}$ de prolina em relação concentração de $0 \mathrm{mmol}^{-1}$ de $15,4 \%$ (Tabela 3). O fechamento estomático é um mecanismo adaptativo das plantas para evitar perdas excessivas de água principalmente sob condições de estresse. No entanto, ao interferir na atividade fotossintética, limitando a entrada de $\mathrm{CO}_{2}$ pelo poro estomático, esse mecanismo pode ocasionar redução na produção de fotoassimilados, refletindo no crescimento e produtividade, como observado por Feijão et al. (2011) em trabalho realizado com sorgo sudão, e por Neves et al (2009) em feijão de corda.

A fotossíntese, a transpiração, a condutância estomática e a concentração intercelular de $\mathrm{CO}_{2}$, são parâmetros que por sua vez diagnosticam mudanças no comportamento fisiológico das plantas, quando submetidas a condições adversas, como, por exemplo, a salinidade. Deste modo, tem-se observado uma redução na fotossíntese, transpiração, condutância estomática, e redução ou aumento na concentração intercelular de $\mathrm{CO}_{2}$, isto a depender do tipo de estresse que a planta foi submetida (LORETO et al., 1997), em sua maioria essa diminuição é atribuída à redução na aquisição de $\mathrm{CO}_{2}$ pelo fechamento estomático.

\section{CONCLUSÃO}

As variáveis de crescimento e acúmulo de massa foram comprometidas pelo aumento da salinidade do solo.

As trocas gasosas em especial a transpiração e a concentração interna de carbono foram influenciadas pela aplicação das diferentes concentrações de prolina.

\section{REFERÊNCIAS}

ABDELGAWAD, H.; ZINTA, G.; HEGAB, M. M.; PANDEY, R.; ASARD, H.; ABUELSOUD, W. High salinity induces different oxidative stress and antioxidant responses in maize seedlings organs. Frontiers in Plant Science, v.7, n.276, 2016. https://doi.org/10.3389/fpls.2016.00276

ASHRAF, M.; AKRAM, N. A.; ALQURAINY, F.; FOOLAD, M. R. Drought tolerance: roles of organic osmolytes, growth regulators, and mineral nutrients. Advances in Agronomy, v.1, n.11 p.249-296, 2011. https://doi.org/10.1016/B978-0-12-387689-

\subsection{2-3}

ASHRAF, M.; FOOLAD, M. R. Roles of glycine bataine and praline in improving plant abiotic stress resistence. Enviromental and Experimental Botany, Kidlington, v.59, n.2, p.2006-2016, 2007. https://doi.org/10.1016/i.envexpbot.2005.12.006

AYERS, R. S.; WESTCOT, D. W. A qualidade da água na agricultura. 2. ed. Campina Grande: UFPB, 1999. 153p. (Estudos FAO, Irrigação e Drenagem, 29).

BAYUELO JIMÉNEZ, J. S.; JASSO PLATA, N.; OCHOA, I. Growth and Physiological Responses of Phaseolus Species to salinity Stress. International Journal of Agronomy, 2012. https://doi.org/10.1155/2012/527673

CONAB. Acompanhamento da safra brasileira de grãos: v.5 - Safra 2017/18, n.4, 40 levantamento. Brasília: CONAB, 2018. 132p. 
D'ODORICO, P.; BHATTACHAN, A.; DAVIS, K. F.; RAVI, S.; RUNYAN, C. W. Global desertification: Drivers and feedbacks. Advances in Water Resources, v.51, p.326- 344, 2013. https://doi.org/10.1016/i.advwatres.2012.01.013

FAO. Statistical databases - production. 2005.

FEIJÃO, A. R.; SILVA, J. C. B.; MARQUES, E. C.; PRISCO, J. T.; GOMES FILHO, E. Efeito da nutrição de nitrato na tolerância de plantas de sorgo sudão à salinidade. Revista Ciência Agronômica, v.42, n.3, p.675-683, 2011. https://doi.org/10.1590/S1806$\underline{66902011000300014}$

GALVÃO, J. C. C.; MIRANDA, G. V.; TROGELLO, E.; FRITSCHE-NETO, R. Sete décadas de evolução do sistema produtivo da cultura do milho. Revista Ceres, v.61, supl., p.819-828, 2014. https://doi.org/10.1590/0034-

\section{7×201461000007}

GERLAND, P.; RAFTERY, A. E.; SEVCIKOVA, H.; KI, N.; GU, D.; SPOORENBERG, T.; ALKEMA, L.; FOSDICK, B. K.; CHUNN, J.; LALIC, N.; BAY, G.; BUETTNER, T.; HEILIG, G. K.; WILMOTH, J. World population stabilization unlikely this century. Science, v.346, n.6206, p.234-237, 2014. https://doi.org/10.1126/science.1257469

GOMES, K. R; AMORIM, A. V.; FERREIRA, F. J.; A FILHO, F. L; LACERDA, C. F; GOMES FILHO, E. Resposta de crescimento e fisiologia do milho submetido a estresse salino com diferentes espaços de cultivos. Revista Brasileira de Engenharia Agrícola e Ambiental, v.15, n.4, p.365 -370, 2011. https://doi.org/10.1590/S1415$\underline{43662011000400006}$

GONDIM, F. A.; MIRANDA, R. S.; GOMES-FILHO, E.; PRISCO, J. T. Enhanced salt tolerance in maize plants induced by $\mathrm{H} 2 \mathrm{O} 2$ leaf spraying is associated with improved gas exchange rather than with non-enymatic antioxidant system. Theoretical and Experimental Plant Physiology, v.25, n.4, p.251-260, 2013. https://doi.org/10.1590/S2197$\underline{00252013000400003}$

ISLÃ, R.; ARAGUÉS, R. Yield and plant ion concentrations in maize (Zea mays L.) subject to diurnal and nocturnal saline sprinkler irrigations.
Field Crops Research, v.116, p.175-183, 2010. https://doi.org/10.1016/i.fcr.2009.12.008

JIANG, C.; CUI, Q.; FENG, K.; XU, D.; LI, C.; ZHENG, Q. Melatonin improves antioxidant capacity and ion homeostasis and enhances salt tolerance in maize seedlings. Acta Physiologae Plantarum, v.38, n.82, 2016. https://doi.org/10.1007/s11738-016-2101-2

KUZNETSOV, V. V.; SHEVYAKOVA, N. I. Stress responses of tobacco cells to high temperature and salinity. Proline accumulation and phosphorylation of polypeptides. Physiologia Plantarum, Copenhagen, v.100, n.2, p.320-326, $1997 . \quad$ https://doi.org/10.1034/i.1399$\underline{3054.1997 .1000214 . x}$

Lacerda, F. H. D.; Pereira, F. H. F.; Silva Neves, D.; Costa Borges, F. Q.; Júnior, J. E. C. Aplicação exógena de prolina na redução do estresse salino em meloeiro. Revista Verde de Agroecologia e Desenvolvimento Sustentável, v.7, n.3, p. 218227, 2012.

LACERDA, F. H. D. Aplicação exógena de prolina no crescimento fisiologia e produção da melancieira irrigada com água salina. 2013. Ano de obtenção. 2013. 39p. Monografia (Curso de Agronomia)- Universidade Federal de Campina Grande, Centro de Ciências e Tecnologia Agroalimentar, Pombal-PB, 2013.

Lima, C. J. G. S.; Oliveira, F. D. A.; Medeiros, J. D.; Oliveira, M. K. T.; Almeida Júnior, A. D. Resposta do feijão caupi a salinidade da água de irrigação. Revista Verde de Agroecologia e Desenvolvimento Sustentavel, v.2, n.2, p.79-86, 2007.

MANE, A. V; DESHPAND, T. V; WAGH, V. B; KARADGE, B. A; SAMANT, J. S. A. Critical review on physiological changes associed with reference to salinity. International Journal of Environmental Science, v.1, p. 1192 -1216, 2011.

PITANN, B.; MOHAMED, A.; NEUBERT, A. B.; SCHUBERT S. Tonoplast $\mathrm{Na}+\mathrm{H}+$ antiporters of newly developed maize (Zea mays L.) hybrids contribute to salt resistance during the second phase of salt stress. Journal of Plant Nutrition and Soil Science, v.176, n.2, p.148-156, 2013. https://doi.org/10.1002/jpln.201200597 
ROY, D.; BASU, N.; BHUNIA, A.; BANERJEE, S.K. Counteraction of exogenous L- proline with $\mathrm{NaCl}$ in salt-sensitive cultivar of rice. Plant Biology, Hobeken, v.35 n. 1 p. 69-72, mar, 1993. https://doi.org/10.1007/BF02921122

SILVA, J. F.; ALVES, S. S. V.; OLIVEIRA, F. A.; SILVA JUNIOR, M.J.S.; NASCIMENTO, I.B. Uso de águas salinas como alternativa na irrigação e produção de forragem no semiárido nordestino. Revista Brasileira de Engenharia Agrícola e Ambiental, v.18, suplemento, p.66-72, 2014. https://doi.org/10.1590/1807-

1929/agriambi.v18nsupps66-s72

TAIZ, L.; ZEIGER, E.; MOLLER, I. A.; MURPHY, A. Água e células vegetais. In: Fisiologia e Desenvolvimento Vegetal. 6. ed. Porto Alegre: Artmed, 2017. 855p.

TAVARES FILHO, A. N.; BARROS, M. F. C.; ROLIM, M. M.; SILVA, E. F. F. Incorporação de gesso para correção da salinidade e sodicidade de solos salinos-sódicos. Revista Brasileira de engenharia Agrícola e Ambiental, v.16, n.3, p.247-252, 2012. https://doi.org/10.1590/S141543662012000300002 